\title{
PHILOLARGEA
}

Philologica Canariensia 21 (2015), 133-149 eISSN: 2386-8635

DOI: 10.20420/PhilCan.2015.0037

\section{MARGO GLANTZ, NARRAR LA FASCINACIÓN}

\author{
JULIETA VIÚ
}

Universidad Nacional de Rosario - CONICET, Argentina

\begin{abstract}
RESUMEN
A finales de los setenta y principios de los ochenta, Margo Glantz (1930) comienza a escribir, en diarios y revistas de México, crónicas que abordan la moda en relación con el cine, la pintura y la literatura. A principios del siglo XXI, la temática de la moda ingresa en el terreno de la ficción y se convierte en un tópico. "Zapatos: andante con variaciones" resulta sumamente elocuente para reflexionar sobre esa ficcionalización que se concreta a través de lo que denominamos "narrar la fascinación". Glantz construye una historia sobre las fantasías que genera acceder a objetos de lujo, y que alcanza a todos los consumidores independientemente de su posición económica. En este sentido, es productivo analizar el relato a partir de la perspectiva del capitalismo como religión, propuesta por Walter Benjamin.
\end{abstract}

PALABRAS ClAVE: Margo Glantz, narrativa latinoamericana, moda, capitalismo

\section{Margo Glantz, Narrating the Fascination}

\section{ABSTRACT}

Toward the end of the seventies and the beginning of the eighties, Margo Glantz (1930) starts publishing, in Mexican newspapers and magazines, chronicles that discuss fashion in relation to films, painting and literature. At the beginning of the 21st century, the subject matter of fashion enters the sphere of fiction and becomes a topic. "Zapatos: andante con variaciones" lends itself eloquently to reflecting upon the fictionalization materialized through what we shall call narrating the fascination. Glantz builds a story about the fantasies generated by consumers having access to luxury items regardless their economic position. Therefore, it is productive to analyze this narrative taking as our basis Walter Benjamin's view of capitalism as a religion.

KEYWORDS: Margo Glantz, Latin American narrative, fashion, capitalism

Este artículo se distribuye bajo una licencia Creative Commons Reconocimiento-NoComercial—SinObraDerivada 4.0 
"La moda no es sólo la moderna medida del tiempo, sino que encarna la transformada relación entre sujeto y objeto que resulta de la 'nueva' naturaleza de la producción de mercancías"

Susan Buck-Morss, Dialéctica de la mirada

"El consumo no es la compra: abarca escenarios y dimensiones que -más allá de parecernos racionales o delirantes- lo convierten en un hecho social complejo que recorre la totalidad de nuestra vida"

José Miguel Marinas, La fábula del bazar

\section{LITERATURA, CAPITALISMO Y MODA}

"Zapatos: andante con variaciones", que abre la obra Historia de una mujer que caminó por la vida con zapatos de diseñador (2005), ${ }^{1}$ de Margo Glantz, narra a partir de fragmentos la pasión que Nora García siente por el calzado de diseñador. Esta obsesión que estructura el relato se construye principalmente con recuerdos de la protagonista: situaciones de infancia y de juventud, los modelos que tuvo y los que deseó, las marcas y los diseñadores preferidos. La narración se tensa entre el amor incondicional hacia los zapatos y los problemas de salud que éstos le han provocado. Glantz aborda problemáticas de nuestra cultura contemporánea como el fanatismo, la idolatría, los estereotipos de belleza y el consumo de firmas prestigiosas. Asuntos que convergen, incumben a, y constituyen el fenómeno de la moda - definido por Gilles Lipovetsky como una realidad sociohistórica, característica de Occidente y de la propia modernidad, que se estructura por la lógica de la seducción y lo efímero. ${ }^{2}$ En este sentido, consideramos la moda como expresión por antonomasia de lo que Walter Benjamin denomina la religión capitalista.

En El capitalismo como religión, uno de sus escritos tempranos, ${ }^{3}$ Benjamin concibe el modo de funcionamiento de este sistema económico como una religión, en tanto el capitalismo se constituye en un conjunto de respuestas relacionadas con la satisfacción. Las principales características de esta estructura serían: una religión de puro culto sin dogmas que implicaría la primacía del culto sobre la doctrina; en segundo lugar, se trataría de un culto permanente, esto es, sin tregua y sin misericordia; y, en tercer lugar, debido al carácter gravoso del culto, no se buscaría la expiación de la culpa sino que se la engendraría. Es importante señalar que la palabra 'culpa' en alemán puede también significar deuda económica. ${ }^{4} \mathrm{Al}$ profundizar en la motivación religiosa del capitalismo, Norbert Bolz afirma que, en nuestra sociedad contemporánea, el contenido de esta religión está relacionado con el 
ritual de la moda a través del culto a las mercancías. Según Bolz, el mundo del consumo nos obliga a vivir bajo el politeísmo de las marcas y las modas. Ciframos aquí el punto de partida de nuestro análisis ya que, en "Zapatos: andante con variaciones”, Nora García, envuelta en una fiebre devota, le rinde culto a los Ferragamo. En consonancia con el planteamiento de Bolz, Gilles Lipovetsky, en El lujo eterno. De la era de lo sagrado al tiempo de las marcas (2004), observa una diferencia entre la dádiva en la época sagrada, marcada por el ritual de las fiestas dedicadas a los dioses, y el lujo moderno, esto es, en el tiempo acumulativo y permanente del consumo, donde ya no se trata de dar testimonio de pertenencia a una clase sino de expresar una singularidad. Este recorrido filosófico que enfatiza la idea de una nueva inscripción social de la suntuosidad a partir del paso de la sociedad sagrada a la profana esclarece, en cierta medida, la hipótesis del capitalismo como una religión de culto permanente.

Ese rasgo distintivo de las sociedades contemporáneas que, según las perspectivas señaladas anteriormente, se cifra en la imbricación entre lo religioso y lo económico; esa relación de contigüidad entre campos que, a simple vista, parecerían no estar vinculados, resulta fundamental en el sistema capitalista. Nos urge reflexionar sobre el lugar que el fenómeno de la moda ocupa en él, entendiendo por esta última, no la referencia a la vestimenta, sino, como adelantamos en el epígrafe mediante la cita de Susan Buck-Morss, una dinámica singular entre el sujeto y el objeto en una sociedad productora de mercancías (1995, 114). Esta concepción relacional de la moda, más allá de la mercancía en sí, permite analizar de qué manera, en el relato de Margo Glantz, la búsqueda incansable por adquirir un producto de lujo representa el modus operandi del capitalismo. En particular, nos interesa arrojar luz sobre la construcción del personaje principal, quien, atravesado por la dinámica de la moda, anhela poseer un objeto de culto. La fascinación que guía a la protagonista evidencia el ritual de la moda en el templo del mercado.

\section{NORA GARCÍA}

La protagonista de la historia parece, a simple vista, un personaje muy simple, pero tiene su complejidad. Por sus recuerdos de juventud, parecería una mujer de escasos recursos empleada en un local comercial, y que lleva una vida con ciertas carencias. Sin embargo, a medida que avanza la narración, nos enteramos de que ha viajado por distintas partes del mundo y que posee un capital simbólico importante, evidente tanto por sus conocimientos de 
literatura como de diseñadores y productos prestigiosos. ${ }^{5}$ Sin que Glantz se detenga en ello, con estos nuevos datos, la caracterización de la protagonista gana fuerza. La falta de dinero ocupa un lugar importante en el relato. Sin embargo, éste no apunta a un problema de clases sociales sino al consumismo. Nora, atrapada en el mundo de la moda, fantasea no solo con los productos, sino también con la vida de Yves Saint Laurent, Coco Chanel, Giorgio Armani, Manolo Blahnik y Christian Lacroix, entre otros. A pesar de sufrir serios problemas en los pies, la protagonista se vuelve una fanática del famoso diseñador italiano Salvatore Ferragamo. Anhela por sobre todas las cosas comprarse un par de zapatos de esta marca -en principio-, ya que imagina que tienen la capacidad de rejuvenecerla, de convertirla en objeto de deseo y de devolverle la confianza en sí misma. Sin embargo, Nora no nació "en sábanas de seda ni probó sus primeros alimentos con cucharita de plata. Estaba empleada en una zapatería de provincia que vendía modelos (imitaciones) del Centro a precios asequibles” (13). Esta situación poco holgada que padece Nora no le impide soñar con llegar a ser Cenicienta - dirá irónicamente el personaje- y levantarse "una hermosa mañana y encontrar a un Príncipe Azul en la cocina, acompañado de un criado que en las manos llevara un suntuoso estuche forrado de raso de seda color púrpura y en su interior ostentara la famosa e incorruptible zapatilla de cristal” (13).

A través del humor, se plantea entonces que el impedimento de Nora para comprarse los zapatos es económico. Pero, además, se apela a la ironía mediante la historia que se quiere contar: la de una mujer que caminó por la vida con zapatos de diseñador. La cita anterior, la de Cenicienta y su zapatito de cristal, es una burla al tratamiento serio de temas elevados - por decirlo en términos aristotélicos-, como también al tono solemne que caracteriza a las memorias y las biografías. Recordemos que Nora quiere escribir su autobiografía, pero aquí no hay heroína ni acontecer trágico, sino que se trata de

una mujer (quizá yo misma) que ama desesperadamente y la consecuencia de cuyo amor fatal no es el suicidio, al estilo de Anna Karenina echándose a las vías del tren o de Madame Bovary tomando arsénico para pagar sus deudas o de Madame de Clèves entrando a un convento para no ceder al amor carnal; no, su tragedia consiste en una paulatina deformación del pie izquierdo que le produce un dolor continuo y mediocre (opacado por analgésicos). (15) 
El desafío de escribir la historia de una vida mediocre aparece tematizado en la propia narración. La protagonista, que encarna las paradojas de la moda, narra el relato en clave de farsa. "Si de géneros se trata, no se encuentra aquí lo 'memorable', justamente, de las memorias, sino, por el contrario, el relato de lo poco digno de ser escrito; y además contado por un sujeto muy poco excepcional" (Zanin, 2003, 187). El apellido corriente de la protagonista coopera con la parodia, ${ }^{6}$ reforzada por la tensión que se establece entre los dos espacios por los que se mueve Nora. Se desplaza, al menos en sus recuerdos, del consultorio del médico o de la podóloga a la boutique de zapatos, y viceversa.

Este tratamiento en clave humorística del consumismo, si bien evidencia cierto nivel de conciencia de la protagonista sobre su problema, en realidad trata de visibilizar su condición de esclava ante la tiranía de la moda. Nora está convencida, por la publicidad, de que para ser una mujer atractiva es necesario usar zapatos de tacón alto. Citamos un fragmento ilustrativo: "en el terreno sexual, tanto si lo reconoce o no, una mujer como yo, Nora García, puede elegir entre convertirse en el sujeto o en el objeto de la adoración masculina. Físicamente, una no puede encogerse si usa tacones altos, nos obligan a llevar el porte erguido, como quien dice, a adoptar una pose" (32). Hay dos motivaciones que mueven a Nora en la búsqueda de los zapatos: una es comprarse unos Ferragamo; la otra, escribir una novela autobiográfica "que tiene relación con un camino por andar" (26). El título del libro (Historia de una mujer que caminó por la vida con zapatos de diseñador) se refiere justamente a la obra que analizamos. En este sentido, observamos que Nora se encuentra sometida a la tiranía de la moda también cuando le otorga un carácter fetichista a los zapatos. La idea de que no logrará escribir su historia si no está bien calzada es un pensamiento recurrente de la protagonista.

\section{LOS FERRAGAMO, UN FETICHE}

Los zapatos comparten con Nora García el papel protagónico. Ello se vuelve evidente en el título del libro y también por la gran cantidad de relatos intercalados que, en "Zapatos: andante con variaciones”, de una u otra manera, abordan el tema del calzado. Nos referimos a los fragmentos dedicados a los pies de las estatuas, a los Carmelitas Descalzos y a Vera Nabokov, entre otros. El vínculo fetichista que se establece entre el sujeto y el objeto se encuentra en suspenso, ya que la compra será continuamente postergada. En distintas ocasiones, la protagonista pasea frente al local, mira la vidriera, entra a la boutique y hasta se 
prueba el par; sin embargo, el intercambio no se concreta. Esta demora en la adquisición del objeto provoca en la protagonista una mayor idealización, que a su vez intensifica el deseo de posesión. A medida que pasa el tiempo, Nora encuentra nuevas razones para comprarse los zapatos: con tacones altos, afirma el personaje, "una mujer común y corriente se transforma en una vampiresa" (14). ${ }^{7}$ De todas maneras, nos centramos, no en el protagonismo de este objeto de lujo, sino en la tensión que Nora establece con él y que lo vuelve fundamental en relación con el culto a la moda.

El zapato en tanto mercancía, en el sentido dado por Marx, presenta dos caras. El valor de uso, que corresponde a la capacidad que el objeto tiene de satisfacer una necesidad (cualidad intrínseca al objeto); y el valor de cambio, relacionado de manera directa con el consumo, dependiente del intercambio económico (carácter contingente). La pregunta que nos hacemos ante ello es: ¿qué sucede con ambos valores cuando de unos zapatos comunes y corrientes pasamos a los Ferragamo? Esto es, ¿qué sucede con las dos caras de la mercancía cuando interviene el diseñador como firma? En principio, este fenómeno, regido por valores como la novedad y la exclusividad, incumbe al valor de cambio. Los zapatos de diseñador, que cotizan en el mercado de la moda, evidencian la preponderancia del valor de cambio sobre el valor de uso. Esto se observa desde el comienzo del relato, cuando la protagonista expresa que no quiere el par para caminar sino para sentarse a escribir. Al alterar la finalidad propia del objeto, el valor de uso no solo queda desplazado sino directamente fuera de juego.

"A pasos ciegos me dirijo de nuevo a Ferragamo, donde he visto los zapatos, sé que no podré escribir mi novela si no estoy bien calzada" (31), sentencia Nora. El convencimiento que manifiesta esta afirmación trasluce el carácter permanente del culto. El fetichismo de la mercancía - como lo concibe Marx - se encuentra ligado a una creencia o práctica religiosa en la que ciertos objetos aparecen dotados de poderes mágicos. Giorgio Agamben señala que a la preponderancia del valor de cambio sobre el valor de uso le corresponde, en el fetichismo, la superposición de un valor simbólico particular al uso normal del objeto (2002, 62). Los zapatos se convierten en un fetiche a partir de que Nora los considera imprescindibles para escribir su autobiografía. Como desarrollaremos más adelante, simbólicamente, los Ferragamo están relacionados con el éxito: una mujer que logra caminar con zapatos de diseñador por la vida es alguien que ha triunfado - al menos así lo entiende Nora. Este anhelo de éxito no puede entenderse del todo sin referirnos al vínculo familiar que la protagonista tiene con el calzado (historia asociada al fracaso). Desde su infancia, Nora 
estuvo en contacto con ese mundo, ya que sus padres tuvieron una zapatería y su tío fue zapatero. Sin embargo,

los zapatos que mi madre vendía en su zapatería de pueblo estaban hechos concienzudamente a mano, e imitaban sin saberlo los diseños de Ferragamo, y en Neiman Marcus de Dallas se vendían aproximadamente a cuarenta dólares de esa época, suma exorbitante si se piensa que nosotros, lo subrayo, los vendíamos a veintitrés cincuenta el par, y el peso estaba a dos cuarenta y cinco por un dólar. (21)

La protagonista vive como un verdadero asedio la relación que su familia ha tenido con el calzado. En la cita, se refleja claramente la tensión centro/periferia y su proyección en la desvalorización de lo producido en este último caso. Los padres de Nora tuvieron una zapatería de barrio, donde no se podían vender más que productos baratos. De aquí se desprende otra problemática afín, la idea de que la diferencia en la calidad repercute simbólicamente en el objeto. No es lo mismo un par original que una copia: los zapatos que los García vendían eran imitaciones. Esta vida común y corriente se refuerza con la profesión de su tío Iván "que era zapatero, profesión nefasta, vergonzosa para la familia, sobre todo si se tiene en cuenta que ese tío ni siquiera producía un par de zapatos entero, apenas la parte superior del calzado sin la suela" (17). Este relato de Nora sobre su historia familiar vuelve evidente (y abismal) la diferencia entre un zapatero y un diseñador. Su tío fue un empleado que se dedicó a construir una ínfima parte del objeto, mientras que Ferragamo fue un creador capaz de diseñar el zapato completo. Las mercancías coleccionables que inventó son piezas únicas fabricadas para estrellas de cine, televisión o personalidades de la cultura. Esto evidencia que la valoración del objeto no radica ya en el tiempo de trabajo invertido para producirlo, sino en el circuito de valor-deseo en el que ingresa y en ese valor-deseo que es capaz de generar en el cliente. Alejados de cualquier tipo de utilidad, los Ferragamo -símbolo de prestigio social- implican para la protagonista poder tener o ser lo que no ha tenido o no ha sido, y aquí se juega, de manera decisiva, el anhelo de Nora. Como señala Jean-Joseph Goux, a partir del cuento de Voltaire El mundo tal como va, visión de Babouc escrita por él mismo, es el capricho o la fantasía de los hombres lo que establece el valor de las cosas frívolas $(2011,19)$. Por supuesto, como veremos más adelante, el deseo de la protagonista por esos zapatos en particular viene determinado por la firma y la marca, que simbolizan, entre otras cuestiones, la exclusividad y la originalidad. 
El relato pone en escena el culto a la religión capitalista a través del fetichismo que Nora García evidencia hacia los Ferragamo. Para una mujer que vive en el tiempo de las marcas - en palabras de Lipovetsky-, su fetiche no puede ser sino un producto de moda. Esta creencia, sustentada en la publicidad, se representa en la obra en términos amorosos. Se trata de "una mujer que amó demasiado" (19), afirma la protagonista en el intento por volver heroico el relato.

\section{NARRAR LA FASCINACIÓN}

Margo Glantz construye "Zapatos: andante con variaciones" como una narración sobre el anhelo obsesivo de Nora García. La obstinación de la protagonista con el calzado se debe en buena medida a la seducción que éste ejerce sobre ella ya que el objeto se presenta irresistible ante los ojos del fanático. Ponemos énfasis en los aspectos subjetivos que, junto con los objetivos, conforman la base de todo consumo, ${ }^{8}$ debido a que limitarlo al intercambio comercial es simplificar el fenómeno. Narrar la fascinación supone otorgarle protagonismo a los sentimientos, deseos y fantasías, a la vez que a la experiencia corporal y cultural que la adquisición de un objeto pone en juego. Desde esta perspectiva, la compra de los Ferragamo no se convierte en una escena más, sino que constituye la posibilidad misma de que haya relato. El núcleo se encuentra, así, ubicado al final, cuando se narra justamente la realización de la compra soñada. La historia en su totalidad está motivada por esta compra, tanto que cuando finalmente Nora obtiene los zapatos el relato concluye. Nunca sabremos si la protagonista logró iluminarse para escribir su historia; solamente sabemos que obtuvo el objeto deseado.

El encantamiento de la protagonista puede pensarse, en parte, a partir de eso que Georg Simmel denomina el problema del hombre moderno; esto es, el problema religioso, ya que, si bien ha tenido lugar un cambio en los contenidos de la fe, ello no afecta a la fe en sí misma:

Lo que subsiste hoy no es ya la forma vacía de la trascendencia, que busca un nuevo contenido con que llenarse, sino algo mucho más profundo: la necesidad, el anhelo que, en general, se apacigua con lo trascendente: en suma, una realidad espiritual que, al suprimirse los contenidos de la fe, parece paralizarse y apartarse del camino que lleva a la plena vida (Simmel, 2005 [1911], 15) 
Esa necesidad religiosa de los sujetos deseantes que persiste en las modernas sociedades secularizadas mueve a Nora hacia la compra, momento que otorga sentido a su vida. Todos los recuerdos del personaje colaboran en la construcción de esa fe (siempre ciega en tanto no admite réplicas) en el culto a las mercancías. Como veremos en los apartados siguientes, la creencia que profesa Nora hacia los objetos de lujo se basa principalmente en expresiones auráticas de la moda.

Esta historia de amor - entre Nora y los zapatos-, de encuentros y desencuentros, tiene lugar en el escenario del nuevo mercado del lujo, como llamará Lipovetsky al espacio cultural contemporáneo que se ha caracterizado en las últimas dos décadas del siglo XX por el despliegue de

el 'derecho' a las cosas superfluas para todos, el gusto generalizado por las grandes marcas, el auge de consumos ocasionales de sectores más amplios de población, una relación menos institucionalizada, más personalizada, más afectiva con los signos prestigiosos: el nuevo sistema celebra las nupcias entre el lujo y el individualismo liberal $(2004,16)$

Los cambios sociales, económicos y culturales que Lipovetsky observa con respecto al lujo resultan útiles, ya que nos permiten considerar esa relación problemática entre el precio del producto y la posición social de la protagonista, quien finalmente logra acceder a los zapatos una vez que entran en periodo de liquidación. Sin considerar este nuevo escenario de democratización del lujo, que, en cierta medida, vuelve más accesible los objetos exclusivos, no es posible entender que una mujer de clase baja como Nora pueda, en algún momento de su vida, adquirir estos zapatos.

Narrar la fascinación en la época del capitalismo como religión supone entonces construir un relato del consumo. Los fragmentos que refieren de manera directa a la vida de Nora y a su compra de los zapatos se vinculan con otros con los que parecerían no tener relación y que se vuelven fundamentales. Así, en el apartado diecisiete, se cuenta que Catalina de Médicis fue la primera mujer que utilizó zapatos de tacón, y el veintiséis refiere a una nota de una revista sobre el hallazgo de una reliquia: un par de zapatos del siglo XVII. Con estos y otros pasajes más, el personaje en primera persona va formando una imagen de 
su obsesión a través de una serie de referencias como las aludidas que adquieren sentido en relación con la historia principal.

\section{EL RITUAL DE LA MODA}

Detengámonos en la escena final cuando Nora García vuelve - después de varias idas y venidas - al local y decide comprarse los zapatos, momento en el que se completa el ritual de la moda. Allí se conjugan aspectos propios de lo religioso, como el culto, la devoción y la veneración, con aspectos económicos y culturales, como la importancia de la firma, la exclusividad y originalidad del producto, la fama y el glamour. Veamos la escena:

Usted ya estuvo aquí, Nora asiente, ruega que se los muestre de nuevo, los contempla, los acaricia, se los pone, verifica que no se le note demasiado el juanete, se decide, se los quita, se encamina a la caja y los paga, pero antes de hacerlo pronuncia un voto, una manda a Santa Teresa de Jesús: usarlos solamente cuando se siente a escribir, como ahora lo hace, con los zapatos puestos, los zapatos Ferragamo que ha comprado en una exclusiva boutique de la calle Bond en Londres; acompañando al calzado, unas medias de ese mismo color, exacto color (se comprará luego varios pares de nailon de la marca Fogal, pues son las únicas medias que entonan bien con los zapatos del gran artesano, corrijo, idel más grande artista del calzado!, iaunque fuera fascista!). (46)

Detenernos en la escena de manera general permite observar que el ritual de la moda - entendido como experiencia corporal, cultural y, sin lugar a dudas, económicacomienza por la devoción que siente Nora. Momento mágico, podríamos decir, de ensueño, donde la protagonista, en el gesto de contemplar y acariciar los zapatos, manifiesta no solo la concreción de un deseo, sino también el carácter sagrado que les adjudica. Siente una atracción particular hacia esos zapatos que "están colocados en una mesa redonda situada en el centro de la tienda” (37). Esta distribución geográfica se vuelve significativa, ya que el altar, en este caso la mesa donde se encuentra el objeto de adoración, está ubicado en el corazón de la escena. La seducción que experimenta la protagonista es predominantemente visual. "Desde la ventana entreabierta de la zapatería puedo admirar la vitrina que exhibe los zapatos", (24) comenta en uno de los paseos anteriores. Después de este primer contacto, los 
acaricia. Ambos, la mirada y la caricia, expresan, a nuestro modo de ver, la devoción o inclinación amorosa.

La mercancía se vale de distintos mecanismos de la moda para seducir al comprador a través de los sentidos. Las formas de apropiación del objeto a las que nos referimos hace un momento (es decir, ver, sentir, percibir, y desear) constatan el aspecto subjetivo - plantea Cristián Sucksdorf (2013) - del fetichismo, al entender que la doble vida de la mercancía supone la convivencia del sujeto y el objeto de una manera más compleja que como simple inversión de papeles (“cosificación de los sujetos” y "personificación de las cosas”). Con este planteamiento, intentamos priorizar las determinaciones subjetivas (del objeto) por encima de las objetivas. En este sentido, las empresas publicitarias saben que las estrategias de venta no deben orientarse a promocionar los valores de uso sino - como señala Bolz- a la escenificación de las mercancías. Escenificación que se genera no solo por elementos visibles, como la elección del lugar en la vitrina, la forma en que se lo presenta, etcétera, sino también por la fama que conlleva toda marca.

El comportamiento fervoroso de Nora nos lleva a detenernos en dos momentos anteriores a la escena final, donde la protagonista se refiere a la relación particular que los Carmelitas Descalzos han tenido con el calzado. La narración se abre con una breve nota que remite a la etimología de la palabra 'zapato', término que, según el Diccionario de Covarrubias - nos cuenta la narradora- no existía en castellano, por lo que se utilizaban otros como ‘calzas' o ‘calzado’ para designar a aquella persona que llevaba algo en los pies en oposición a los religiosos que andaban descalzos. Otra referencia religiosa del relato (la última, se da en la escena final cuando Nora hace un voto a Santa Teresa), que remite a la misma Orden, expresa lo siguiente:

Una mujer pasa repetidas veces frente a una vitrina, mejor, por una calle donde hay zapatos; su obsesión es doble, está fijada en el calzado y en una novela que tiene relación con un camino por andar, obsesión también recurrente en Santa Teresa, San Ignacio o San Juan y los franciscanos seráficos de México. La idea es trazar un paralelismo entre la mujer que tiene que andar simplemente un camino amoroso o el camino en mezzo del camin di nostra vita, digamos, y, paralelamente, a manera de alegoría, los frailes seráficos, Santa Teresa o San Juan, que andan descalzos o con sus pobres y primitivas sandalias. (27) 
Este fragmento pone de manifiesto la diferencia entre el sacrificio que hace Nora de soportar el dolor físico que le ocasiona ponerse zapatos de tacón alto, y los Carmelitas Descalzos, orden fundada por Santa Teresa de Jesús y San Juan de la Cruz en España en el siglo XVI, que hacen votos de pobreza personal, obediencia, castidad y clausura. Los religiosos simbolizan el despojo de los bienes materiales, mientras que Nora exhibe un afán fetichista que la lleva a acumular bienes y mercancías. A pesar de esta diferencia, ambos están motivados por una creencia: si en el caso de los Carmelitas Descalzos responde a una fe religiosa, el sacrificio al que Nora somete su cuerpo obedece a un imperativo cultural de belleza. Estas referencias a los religiosos, aunque breves, resultan efectivas porque enfatizan su diferencia con la elección del camino consumista, de lujo y derroche al que conducen las sociedades capitalistas.

\section{EL AURA DE LA MODA}

Fama, exclusividad y glamour, expresiones de aura en términos de moda, son estrategias destinadas a generar una presencia irrepetible del aquí y ahora que convierte al objeto en una singularidad, en términos de Benjamin. Si se trata de la posibilidad de adjudicación del origen, y en ello radica la autenticidad de la mercancía, en el caso analizado el aura se construye a través de distintos mecanismos: por un lado, por el prestigio del artista que se trasmite al producto; y, por otro, por valores como la singularidad y la elegancia con que la moda dota al objeto. En los productos de diseño, la autenticidad es un valor supremo que en el culto al consumo se evidencia claramente. Nora quiere unos Ferragamo, es decir, no quiere otros ni tampoco imitaciones.

Retomemos la escena final para observar de qué manera el relato representa las expresiones de aura mencionadas. Un primer indicio del valor de lo exclusivo aparece en la precisión con que Nora explica cuál es la boutique donde está el calzado que desea. Valor que se presenta como un privilegio y se construye en oposición a lo que es vulgar, regular u ordinario. Que el personaje aclare que se encuentra en la tienda Ferragamo manifiesta la importancia que ella le otorga, ya que no se trata de un local como cualquier otro, o al menos como los que estaba acostumbrada a frecuentar, esto es, las tienditas de barrio que venden zapatos a módico precio. Otro indicio de exclusividad es la referencia a la calle en la que se encuentra la boutique. Momentos antes, la narradora expresa: "Nora, o sea yo, es decir Nora García, recorre Bond Street, pasa por Armani, se pasma ante sus trajes y sobre todo cuando 
entra $\mathrm{y}$ toca la textura de las telas; en Ungaro exhiben vestidos exquisitos, demasiado juveniles (ya no tengo tan estrecha cintura para usarlos); Yves Saint Laurent, maravilloso ..." (30). De manera paulatina, el relato construye a Bond Street - calle donde se ubican las tiendas de los diseñadores más famosos del mundo- como símbolo del lujo.

El reconocimiento universal del diseñador italiano alimenta, al igual que la exclusividad, las fantasías de la protagonista. Escuchemos de qué forma Nora se refiere a dicho éxito: "Pienso de nuevo en Ferragamo, ¿cómo no hacerlo, si uno (más bien una) está obsesionado con los zapatos de alta calidad y magnífico diseño? Sus zapatos dejarán siempre una huella" (34). La fama se encuentra indisolublemente ligada a la construcción de la marca, esa instancia mediadora entre el productor y el consumidor, capaz de expresar la identidad del objeto. Para Nora, todo lo que Ferragamo realiza es excepcional. Xavier Ruiz Collantes, al estudiar el contrato que los productos establecen con los consumidores a través de la marca, sostiene que ésta "debe ofrecer al consumidor una historia en la que pueda actuar como personaje y en la que, al hacerlo, pueda ver realizados sus deseos, sus aspiraciones, sus anhelos y la superación de sus problemas y sus contradicciones, y en la que, por lo tanto, se sienta gratificado" $(2011,62)$. Después de lo analizado, la identificación que Nora siente con estos zapatos resulta obvia. Consumir este producto de lujo no conlleva una ganancia utilitaria, sino una satisfacción simbólica.

Las referencias a Ferragamo presentan una doble función ya que, muchas veces, aluden a la firma y, otras, a la persona de carne y hueso. Nora convierte al diseñador en su ídolo y, por lo tanto, como buena fanática, conoce detalle por detalle su vida. Sabe el día, el mes y el año en que nació; cuántos hermanos tuvo y quiénes fueron sus padres; qué le gustaba hacer cuando era un niño; cuándo diseñó sus primeros zapatos; etc. Además de recordar a la perfección estos datos inútiles que todo fan debe manejar con fluidez, al contar la vida del diseñador, lo primero que hace la protagonista es otorgarle un don: "De la misma manera que Leonardo da Vinci, nacido para pintar a la Mona Lisa y diseñar inventos revolucionarios, Salvatore Ferragamo nació para diseñar zapatos" (13). La habilidad del diseñador para crear modelos es traducida por Nora en términos de predestinación. Señalamos esto para exhibir los mecanismos discursivos sobre los que se construye la figura del ídolo, íntimamente ligada al concepto de fama.

El ferviente sentimiento que despierta Ferragamo se expresa en el relato de manera hiperbólica. Situémonos en el momento en que Nora explicita que los zapatos son "idel más grande artista del calzado! iaunque fuera fascista!”. Estas exclamaciones dejan entrever que 
- como sostiene Benjamin - en la religión capitalista prima el culto sobre la doctrina. El fanático no admite réplica. Que la protagonista considere a Ferragamo un fascista, pero a la vez desee más que nada en el mundo tener uno de sus zapatos, puede parecer contradictorio; sin embargo, si lo relacionamos con el culto adquiere otro sentido: la moda está hecha de paradojas. "Me interesa mucho la vida de Ferragamo. Obsesión curiosa en alguien que tiene los pies deformes y está tirada en la playa con un traje de baño y con los pies descalzos, y ostenta, en uno de los pies, el izquierdo, un juanete imposible de disimular cuando se está descalzo (o descalza), excepto si se entierra el pie completamente en la arena" (40). Nora experimenta en carne propia estos sinsentidos, ya que por verse elegante ha usado calzados de tacón alto de mala calidad y ello le ha provocado serios problemas de salud: "A mí me han ocasionado enfermedades gravísimas empezando por la formación de juanetes, la deformación de la bóveda del pie o la dislocación de la columna vertebral” (14), comenta la protagonista al comienzo de la historia. A pesar de todo, considera que el par de zapatos que vio en la boutique de Bond Street era ideal por estar confeccionado por la persona que realiza "el calzado de las más destacadas señoras de su tiempo, entre las que contaban la esposa de Mussolini y varias artistas de cine (Claudia Cardinale, Sofía Loren, Ingrid Bergman)” (24). El glamour de los Ferragamo, que cautiva y despierta las fantasías de Nora, sumado a la fama y a la exclusividad, constituyen el paradigma de los productos de moda y, por ello, se convierten en referencias recurrentes de la protagonista.

El anhelo de distinción que guía a la protagonista durante todo el relato se vuelve explícito cuando, al referirse a su familia, expresa: "las cosas hubieran mejorado si hubiésemos tenido un destino singular, pero mi padre tuvo una serie de tienditas, una serie de mudanzas, una serie de libros, una serie de hijas y una serie de pinturas y de esculturas que están esperando ser reconsideradas como obras de arte” (17). La serialidad -reforzada por la aliteración - logra otorgarle una carga verdaderamente pesada a esa imposibilidad de cambio que el personaje siente como legado familiar. Observemos una aclaración que hace Nora respecto al par original/copia:

... es de justicia aclarar que sus hormas eran únicas, una para cada pie, es decir, una para el derecho y otra para el izquierdo; la huella de nuestros pies es única, así es la vida o así es la anatomía, un simple designio de la naturaleza. Además, en cada una de sus hormas, Ferragamo escribía el nombre del dueño de los zapatos, ese calzado 
maravilloso que definitivamente permitía y aún permite caminar por el mundo con solidez y natural elegancia. Sus hormas eran perfectas. (40)

Estos zapatos que siempre anheló y que nunca pudo tener representan su objeto de deseo. Por ello, el beneficio que Nora obtendría al poseerlos sería simbólico; en cambio, el calzado que usó (las imitaciones), que han satisfecho sus necesidades, presentan un valor utilitario. No debemos perder de vista que ella espera buena parte de su vida para comprarse los zapatos y que la espera, entendida como distancia, aporta a la sacralización.

A modo de conclusión, el estudio detallado de la escena matriz ha permitido observar cómo, a partir de narrar la fascinación, Margo Glantz logra ficcionalizar uno de los temas que la ha obsesionado a lo largo de su vida. La moda cobra una presencia ineludible en el argumento del relato y en la construcción del personaje principal, y se convierte así en motor de esa historia que termina cuando la protagonista logra cumplir su sueño.

\section{NOTAS}

1 Historia de una mujer que caminó por la vida con zapatos de diseñador (Barcelona: Anagrama, 2005) surge producto de la reescritura de Zona de derrumbe (Rosario: Beatriz Viterbo, 2001). Margo Glantz reordena los relatos originales ("Palabras para una fábula", "Animal de dos semblantes", "Zapatos: andante con variaciones", "English love", "El té con leche" y "Jarabe de pico") y agrega nuevos ("Contingencia", "He soñado", "Una historia de amor" y "Zona de derrumbe"). En particular, "Zapatos: andante con variaciones" fue aumentado y corregido considerablemente. Mientras que la primera versión cuenta con veinticuatro fragmentos, la última se compone de sesenta. Cabe destacar que el relato empieza y termina con las mismas escenas. Por tratarse de una edición más completa, en este artículo trabajaremos con la última versión.

2 En oposición a la concepción de la moda como tendencia psicológica universal, esto es, como un fenómeno de carácter transhistórico (Simmel, 1939 [1902-1911]), Lipovetsky basa su análisis en el vínculo estrecho que liga dicho fenómeno con la modernidad. La moda no es "ni fuerza elemental de la vida colectiva ni principio permanente de transformación de las sociedades enraizado en las características generales de la especie humana" $(2012,24)$, sino que es un fenómeno circunscripto a un tipo de sociedad, la sociedad moderna.

3 Actualmente, los críticos no han llegado a un acuerdo sobre cuál fue la fecha de redacción de $E l$ capitalismo como religión. Existen varias hipótesis; sin embargo, la que presenta más adhesión es la que estima que el escrito tuvo que haber sido producido alrededor de 1921. Esta problemática se analiza en detalle en la introducción a la traducción inédita de "El capitalismo como religión" realizada por Enrique Foffani y Juan Antonio Ennis.

4 Foffani y Ennis (2013) señalan que la palabra culpa - schuld en alemán- presenta "una demoníaca ambigüedad" ya que puede traducirse tanto por 'culpa' como por 'deuda económica'. Ahí radica la base para pensar en una similitud estructural entre el capitalismo y el cristianismo. 
5 Margo Glantz juega con la identificación entre la autora y el narrador-personaje Nora García a través de la alternancia entre la primera y la tercera persona del singular. Este recurso narrativo lo emplea tanto en esta obra como en otras posteriores. Nora García es la protagonista de todos los relatos que conforman Zona de derrumbe (2001) y, por lo tanto, de Historia de una mujer que caminó por la vida con zapatos de diseñador (2005), también de El rastro (2002) y de Simple perversión oral (2014). Nora García, fanática de los zapatos de diseñador, es el alter ego de Margo Glantz.

6 El nombre propio de la protagonista permite establecer un vínculo con la obra teatral Casa de muñecas (1879) de Henrik Ibsen. A partir de la figura de Nora Helmer, el dramaturgo cuestiona el lugar que la mujer tenía a finales del siglo XIX. La obra pone en escena la subordinación de la mujer en relación con el hombre. En este sentido, tal vez a modo de homenaje, Margo Glantz, al abordar la tiranía de la moda sobre la mujer, elige llamar Nora a su personaje. Así como a Helmer los hombres (representados bajo el papel del padre y de su marido) no la dejan ser, Nora García no dispone de su cuerpo porque se encuentra bajo la esclavitud de la moda. Los mecanismos que le impiden liberarse están tan naturalizados y arraigados socialmente (podríamos pensar, por ejemplo, en la imposición de modelos publicitarios de belleza) como el machismo en la Noruega de Ibsen.

7 A este respecto, resulta esclarecedor el planteamiento de Nobert Bolz, en "El capitalismo ¿una invención de los teólogos?” (2003), cuando señala que tanto desde el marketing como desde la publicidad se sabe que "ya no puede vendérseles [a los consumidores] ningún producto que hable por sí mismo. Ya no se trata para ellos del valor de uso, sino del valor de escenificación de las mercancías. Lo que se busca son mundos temáticos, estilos de vida, imágenes del mundo, que deben ser puestos en escena como en el culto".

8 Desde una concepción amplia, el consumo, como sostiene José Miguel Marinas, "abarca escenarios y dimensiones que -más allá de parecernos racionales o delirantes- lo convierten en un hecho social complejo que recorre la totalidad de nuestra vida" $(2001,17)$.

\section{REFERENCIAS BIBLIOGRÁFICAS}

AGAMBEN, G. 2002. Estancias. La palabra y el fantasma en la cultura occidental. Madrid: Editora Nacional.

BENJAMIN, W. 2013 [1923]. El capitalismo como religión. Traducción inédita de Foffani, E. y Ennis, J. A. . 2005 [1982]. "La moda”, en Libro de los pasajes. Madrid: Akal, 91-108. . 2007 [1936]. "La obra de arte en la época de su reproductibilidad técnica”, en Conceptos de filosofía de la historia. La Plata: Terramar, 147-182.

BOLZ, N. 2003. “El capitalismo ¿una invención de los teólogos?”, en Baecker, D. (ed.), Kapitalismus als Religion. Berlin: Kulturverlag Kadmos, 187-207. Traducción inédita de Ennis, J. A. 
BUCK-MORSS, S. 1995. "La moda", en Dialéctica de la mirada. Walter Benjamin y el proyecto de los pasajes. Madrid: Visor, 114-116.

GLANZ, M. "Zapatos: andante con variaciones”, en Historia de una mujer que caminó por la vida con zapatos de diseñador. Barcelona: Anagrama, 2005, 11-46.

GOUX, J. J. 2011. "El precio de las cosas frívolas”, en Caro, A. y Scolari, C. A. (coords.), DeSignis 17. Estrategias globales: Publicidad, marcas y semiocapitalismo. Buenos Aires: La Crujía, 15-23.

LIPOVETSKY, G. 2004. "Lujo eterno, lujo emocional”, en Lipovetsky, G y Roux, E., El lujo eterno. De la era de lo sagrado al tiempo de las marcas. Barcelona: Anagrama, 13-97. . 2012. El imperio de lo efímero. La moda y su destino en las sociedades modernas. Barcelona: Anagrama.

MARINAS, J. M. 2001. La fábula del bazar. Orígenes de la cultura del consumo. Madrid: La Balsa de la Medusa.

MARX, K. 2004 [1867]. "La mercancía”, en El capital, tomo I. Buenos Aires: Siglo XXI, 43-103.

RUIZ COLLANTES, X. 2011. "Marcas para vender historias para vivir. Marca, narración y sentido", en Caro, A. y Scolari, C. A. (coords.), DeSignis 17. Estrategias globales: Publicidad, marcas y semiocapitalismo. Buenos Aires: La Crujía, 6o-68.

SIMMEL, G. 1939 [1902-1911]. Cultura femenina. Filosofía de la coquetería. Lo masculino y lo femenino. Filosofía de la moda. Buenos Aires: Espasa Calpe. . 2005 [1911]. El problema religioso. Buenos Aires: Prometeo.

SUCKSDORF, C. 2013. "El fetichismo de la mercancía y su secreto", en Carpintero, E., Actualidad de El fetichismo de la mercancía. Buenos Aires: Topía, 53-74.

ZANIN, M. 2003. "Cortar el paño del propio traje”, en Manzoni, C. (comp.), Margo Glantz, narraciones, ensayos y entrevistas. Margo Glantz y la crítica. Caracas: Excultura, 187-190. 